\title{
PERCEPÇÃO, PAISAGEM E EDUCAÇÃO AMBIENTAL: UMA INVESTIGAÇÃO COM ESTUDANTES NO MUNICÍPIO DE IRATI, PARANÁ
}

\author{
Mariângela Ceschim Iurk $^{1^{*}}$, Daniela Biondi² ${ }^{2}$ Fernando Luís Dlugosz ${ }^{3}$ \\ ${ }^{1 *}$ Universidade Federal do Paraná, Programa de Pós-graduação em Engenharia Florestal, Curitiba, Paraná, Brasil - mciurk@ yahoo.com.br \\ ${ }^{2}$ Universidade Federal do Paraná, Departamento de Ciências Florestais, Curitiba, Paraná, Brasil - dbiondi@ufpr.br \\ ${ }^{3}$ Universidade Estadual do Centro-oeste, Departamento de Engenharia Florestal, Irati, Paraná, Brasil - f.dlugosz@ gmail.com
}

Recebido para publicação: 13/03/2017 - Aceito para publicação 27/02/2018

\begin{abstract}
Resumo
Esta pesquisa foi realizada durante os meses de maio, junho e julho de 2016 e teve como objetivo verificar a percepção sobre remanescentes florestais pela visão de discentes de onze colégios estaduais do município de Irati (PR), a fim de analisar o quanto a educação ambiental pode estar relacionada aos níveis de conhecimento e atitudes de conservação e preservação do ambiente. Para obtenção dos dados, foi realizada a aplicação de um questionário pré-teste, seguido de uma palestra e, por fim, um questionário pós-teste. Participaram da pesquisa 718 estudantes no pré-teste e 654 no pós-teste, residentes em todos os bairros do município e em 49 comunidades rurais. Por meio da análise de dados de Wilcoxon, constatou-se que $63,7 \%$ das respostas foram significativas ou altamente significativas. A questão 10, que se referia às espécies que compõem a Floresta Ombrófila Mista, foi a que apresentou respostas significativas e altamente significativas. No teste do quiquadrado, rejeitou-se a hipótese de nulidade, pois houve associação entre os grupos dos colégios amostrados. $\mathrm{Na}$ análise do percentual das respostas, a questão 10 apresentou maior acréscimo no percentual, indicando maior reconhecimento das espécies. Dessa forma, trabalhos de educação ambiental são ferramentas extremamente úteis para a mudança de atitudes da comunidade como um todo, garantindo, assim, a conservação das florestas e a manutenção do equilíbrio ambiental.

Palavras-chave: Floresta Ombrófila Mista, conservação, preservação, teste de Wilcoxon.
\end{abstract}

\begin{abstract}
Perception, landscape and environmental education: an investigation with students from the municipality of Irati, state of Paraná, Brazil. This study was carried out during the months of May, June, and July of 2016, and aimed to verify the perception regarding forest remnants based on the vision of students from eleven state schools from the municipality of Irati (state of Paraná, Brazil) in order to analyze how environmental education may relate to the levels of knowledge and conservation and environment preservation attitudes. In order to obtain the data, a pre-test questionnaire was applied, followed by a lecture and, finally, a post-test questionnaire. A total of 718 students participated in the pre-test and 654 students, in the post-test. They lived in all districts of the city and in 49 rural communities. By means of Wilcoxon data analysis, we determined that $63.7 \%$ of the answers were significant or highly significant. Question 10, which referred to the species that compose the Mixed Ombrophilous Forest, was the one that presented significant and highly significant answers. In the chisquare test, the null hypothesis was rejected since there was an association among the sampled groups from schools. Analyzing the percentage of the answers, question 10 presented greater percentage increase, which indicates greater recognition of the species. Therefore, environmental education services are extremely useful tools to change the attitudes of the community as a whole, thus ensuring the conservation of forests and maintaining the environmental balance.
\end{abstract}

Keywords: Mixed Ombrophilous Forest, conservation, preservation, Wilcoxon test.

\section{INTRODUÇÃOO}

Percepção é uma palavra de origem latina (perceptione) que pode ser entendida como a tomada de consciência de forma nítida a respeito de qualquer objeto ou circunstância. A circunstância em questão diz respeito a fenômenos experimentados e vivenciados (MUCELIN; BELLINI, 2008). Assim, a percepção é uma espécie de leitura de mundo que ocorre sob a influência de inúmeros fatores que determinam a atitude do indivíduo em relação ao ambiente percebido. Tratando-se de questões ambientais contemporâneas, as diferentes condutas e formas de relacionamento humano com o seu ambiente refletem essas diferentes vertentes da percepção (OLIVEIRA; VARGAS, 2009).

Isso pode ser observado quando se analisa a qualidade das paisagens. Estudos de percepção constituem uma visão ímpar, uma vez que a investigação e a compreensão dos sentimentos e valores têm um papel importante

FLORESTA, Curitiba, PR, v. 48, n. 2, p. 143-152, abr/jun 2018

Iurk. M. C. et.al.

ISSN eletrônico 1982-4688

DOI: 10.5380/rf.v48 i2.51179 
para a formação de juízos de valor e atitudes que orientam ações sobre os espaços (COSTA; COLESANTI, 2011). Indubitavelmente, só se pode falar de paisagem a partir de sua percepção (COLLOT, 2012), pois está associada à passagem do tempo sobre um determinado local, às percepções das formas e do mundo. Essa percepção passa pela visão que nos conduz a múltiplos processamentos de informações percebidas no meio, onde o arranjo espacial das formas que configura uma paisagem é tão importante quanto o processo cultural que lhe é apropriado (OLIVEIRA et al., 2008).

O estudo da percepção ambiental é de fundamental importância, pois descreve os múltiplos modos de vida reveladores do real sentido de inserção do ser humano em seu ambiente. Somente na redescoberta desses modos de viver e de se relacionar com a natureza, do lugar habitado e da coletividade é que se pode ancorar uma postura sensível e, dessa maneira, serem destinadas ações concretas de educação ambiental (MARIN, 2008).

Embora a escola deva ser um espaço educativo capaz de integrar o indivíduo ao meio ambiente, é preciso estar atento aos outros múltiplos espaços e lugares que têm participação na vida dos sujeitos e sua formação. Nesse contexto, os momentos formativos que se delineiam entre e dentro dos grupos, nos diferentes contextos e espaços, também devem ser considerados. A vivência dos sujeitos, seus saberes, fazeres e seu modo de perceber o mundo representam contribuições relevantes a serem incorporadas pela educação quando se almeja a formação de cidadãos críticos e conscientes (MARCOMIN; SATO, 2016). Em vista disso, o objetivo geral deste trabalho foi verificar a percepção sobre remanescentes florestais pela visão de discentes de colégios estaduais pertencentes ao núcleo regional de Irati (PR).

\section{MATERIAL E MÉTODOS}

\section{Área de Estudo}

A área de estudo (Figura 1) compreendeu o município de Irati, situado no segundo Planalto Paranaense, limitado pelos paralelos $25^{\circ} 11^{\prime}$ e $25^{\circ} 52^{\prime}$ de latitude sul e pelos meridianos $50^{\circ} 27^{\prime}$ e $51^{\circ} 04^{\prime}$ de longitude oeste de Greenwich. e que faz divisa com os municípios de Imbituva, Prudentópolis, Inácio Martins, Rio Azul, Rebouças e Fernandes Pinheiro.
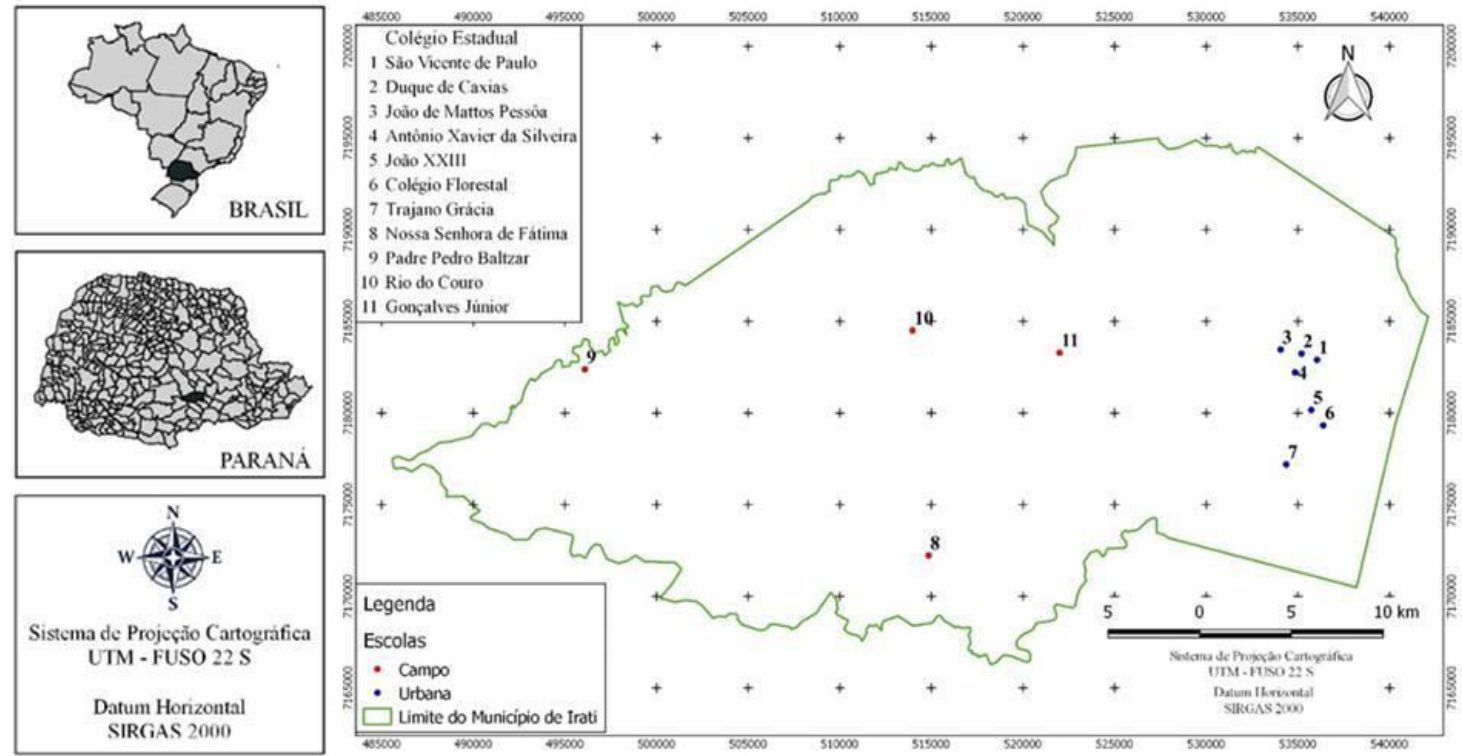

Figura 1. Localização da área de estudo e distribuição territorial dos colégios do município.

Figure 1. Location of the study area and territorial distribution of schools in the municipality.

O município localiza-se na região centro-sul do estado, com altitude média de $812 \mathrm{~m}$. O clima da região, baseado na classificação de Köppen, é do tipo $\mathrm{Cfb}$ : subtropical úmido mesotérmico, caracterizado por verões frescos, geadas severas e frequentes e sem estação seca. A altitude é de $885 \mathrm{~m}$ e a vegetação é caracterizada como Floresta Ombrófila Mista Montana (FIGUEIREDO-FILHO et al., 2010). A população do município de Irati foi estimada em cerca de 60.070 habitantes em 2016 pelo IBGE, e a maior parte da população encontra-se no perímetro urbano (IBGE, 2016).

Em um século de existência, as atividades econômicas, basicamente rurais no início da colonização, diversificaram-se e a área urbana se desenvolveu. A pressão sobre o ambiente aumentou significativamente. O rio das 
Antas, que tem sua nascente e grande parte de seu curso localizados dentro da área urbana do município, apresentou sérios problemas relacionados à qualidade da água e à supressão da floresta ciliar (VENÂNCIO et al., 2010).

Coleta e análise dos dados

Segundo o modelo de avaliação contínua desenvolvido por Jacobson (1991) e adaptado por Padua (2012), foram consideradas três etapas para a obtenção dos dados: Planejamento, Processo e Produto.

Os grupos escolhidos para a realização das atividades foram as turmas dos primeiros anos de colégios do município de Irati, que oferecem o ensino médio. Houve um total de onze colégios, sendo eles: Colégio Estadual de Rio do Couro, Colégio Estadual Padre Pedro Baltzar, Colégio Estadual de Gonçalves Júnior e Colégio Estadual Nossa Senhora de Fátima, localizados no campo; e Colégio Estadual João XXIII, Colégio Estadual Duque de Caxias, Colégio Estadual João de Mattos, Colégio Estadual São Vicente de Paulo, Colégio Estadual Trajano Grácia, Colégio Estadual Antônio Xavier da Silveira e Centro Estadual Florestal de Educação Profissional Presidente Costa e Silva (Colégio Florestal), na região urbana. Na Figura 1, é apresentada a distribuição territorial dos colégios no município.

Inicialmente, foram distribuídos questionários, e foi solicitado aos estudantes que respondessem utilizando os conhecimentos que tinham sobre o assunto e as espécies citadas. Além de responderem questões sobre percepção de remanescentes florestais, os estudantes deveriam informar a idade e o bairro onde residiam, além de há quanto tempo moravam naquele local.

Conforme resolução do Conselho Nacional de Saúde 466/2012, antes do início da aplicação dos questionários, os pais ou responsáveis dos escolares assinaram o Termo de Consentimento Livre e Esclarecido para autorização da realização do estudo. Além disso, os estudantes assinaram o Termo de Assentimento Livre e Esclarecido para a participação na pesquisa. Dessa forma, este trabalho foi autorizado pelo Comitê de Ética em Pesquisa da Universidade Federal do Paraná por meio do Parecer Consubstanciado de número 1.818.208. Na Figura 2, pode-se observar o modelo de questionário aplicado nos colégios.

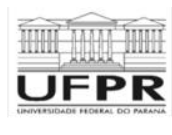

$$
\begin{gathered}
\text { Universidade Federal do Paraná } \\
\text { Programa de Pós-Graduação em Engenharia Florestal } \\
\text { Laboratório de Paisagismo }
\end{gathered}
$$

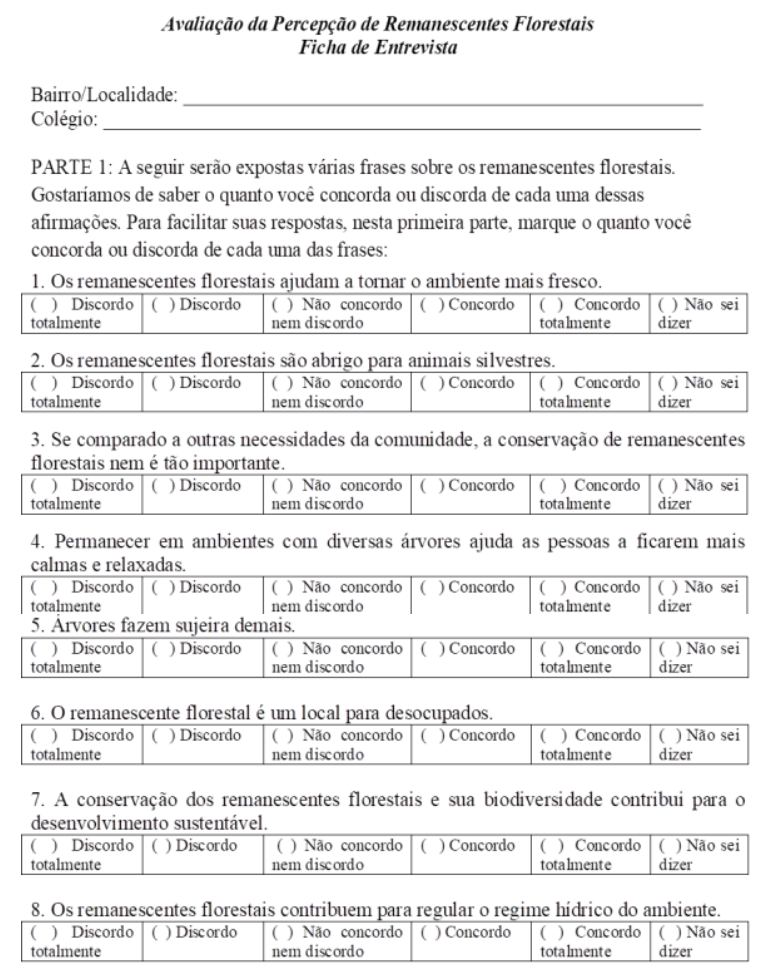

Figura 2. Questionário aplicado nos colégios.

Figure 2. Questionnaire applied at schools.

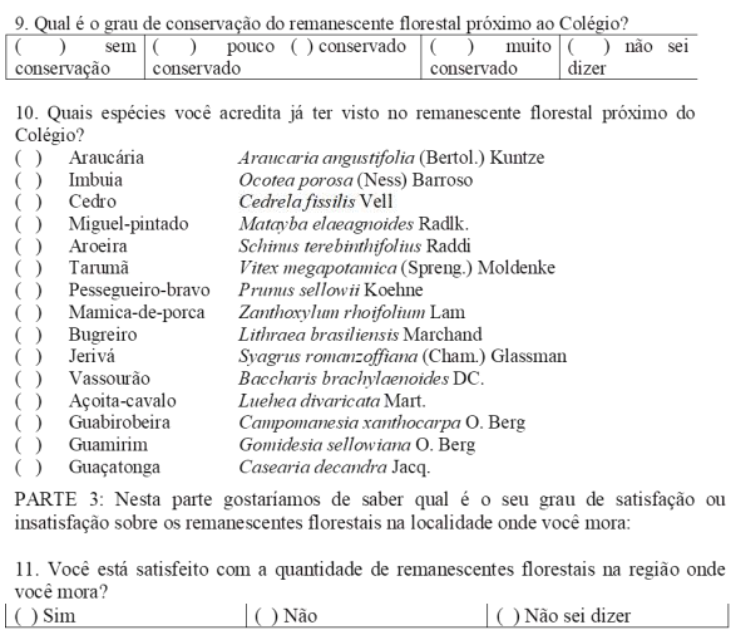

12. Você tem que se deslocar muito até encontrar um local com um remanescente

florestal?
\begin{tabular}{|l|l|l|l|}
\hline ( ) Sim & ( ) Não & ( ) Ás vezes ( ) Não costumo frequentar estes & $\begin{array}{l}\text { ( ) ) Não sei } \\
\text { dizer }\end{array}$ \\
\hline
\end{tabular}

PARTE 4: Caracterização do Entrevistado

13. Gènero: ( ) Masculino ( ) Feminino

14. Idade

15. Há quanto tempo mora nesse local 
Numa data pré-determinada pela direção da escola, uma palestra foi realizada com utilização de projetor multimídia e tablet. Os assuntos tratados referiam-se a: conceituação de um remanescente florestal; fisionomias vegetais do Paraná mais próximas ao município; espécies vegetais que compõem a Floresta Ombrófila Mista; importância ambiental das florestas para a temperatura ambiental; abrigo para animais silvestres e para combater o stress; e conceitos de paisagem, tipos, percepção e as suas modificações. Na sequência da palestra e no mesmo dia, repetiu-se a aplicação do questionário.

As informações foram organizadas de forma a possibilitar a aplicação de análises estatísticas a fim de verificar se ocorreram ou não alterações nas avaliações pré e pós-teste. Foram, então, analisadas:

1 - Mediante teste não-paramétrico de Wilcoxon matched-pairsigned-rankstest (SIDNEY, 1975), foram medidas as diferenças significativas entre pré e pós-testes para cada uma das respostas, adotando-se nível se 5\% de significância, conforme observado em Carrilo e Biondi (2007) e Biondi e Falkowski (2009).

2 - Utilizando o teste do qui-quadrado, comparou-se o resultado obtido entre os colégios, como observado em Fandi e Melo (2001).

3 - Por meio da comparação do porcentual obtido entre o pré e o pós-teste, verificou-se a variação da pontuação obtida pelo estudante.

Para análise estatística da participação dos estudantes, foram realizados cálculos de média, desvio padrão e covariância, confrontando os dados de participação e o número de matrículas.

\section{RESULTADOS}

A coleta de dados foi realizada nos meses de maio, junho e julho de 2016, nos períodos matutino e noturno. Houve um total de 718 estudantes no pré-teste e 654 no pós-teste. Nas Tabelas 1 e 2, pode-se observar a distribuição do número de alunos por colégio, tanto do campo quanto da área urbana do município. Os estudantes tinham de 13 a 21 anos, sendo 362 do gênero masculino e 354 do gênero feminino, residentes em todos os bairros da área urbana e também em 49 comunidades rurais.

Tabela 1. Distribuição do número de estudantes por colégio do campo.

Table 1. Distribution of the number of students per countryside area school.

\begin{tabular}{cccccccc}
\hline \multicolumn{2}{c}{ Gonçalves Jr. } & \multicolumn{2}{c}{$\begin{array}{c}\text { Nossa Senhora de } \\
\text { Fátima }\end{array}$} & \multicolumn{2}{c}{ Padre Pedro Baltzar } & \multicolumn{2}{c}{ Rio do Couro } \\
\hline Pré & Pós & Pré & Pós & Pré & Pós & Pré & Pós \\
21 & 22 & 37 & 18 & 15 & 12 & 30 & 32 \\
\hline
\end{tabular}

Tabela 2. Distribuição do número de estudantes por colégio da área urbana.

Table 2. Distribution of the number of students per urban area school.

\begin{tabular}{|c|c|c|c|c|c|c|c|c|c|c|c|c|c|}
\hline \multicolumn{2}{|c|}{$\begin{array}{c}\text { Antônio } \\
\text { Xavier da } \\
\text { Silveira }\end{array}$} & \multicolumn{2}{|c|}{$\begin{array}{l}\text { Colégio } \\
\text { Florestal }\end{array}$} & \multicolumn{2}{|c|}{$\begin{array}{c}\text { Duque de } \\
\text { Caxias }\end{array}$} & \multicolumn{2}{|c|}{$\begin{array}{l}\text { João de } \\
\text { Mattos } \\
\text { Pessôa }\end{array}$} & \multicolumn{2}{|c|}{ João XXIII } & \multicolumn{2}{|c|}{$\begin{array}{c}\text { São Vicente } \\
\text { de Paulo }\end{array}$} & \multicolumn{2}{|c|}{$\begin{array}{l}\text { Trajano } \\
\text { Grácia }\end{array}$} \\
\hline Pré & Pós & Pré & Pós & Pré & Pós & Pré & Pós & Pré & Pós & Pré & Pós & Pré & Pós \\
\hline 213 & 224 & 96 & 66 & 35 & 32 & 46 & 39 & 89 & 84 & 93 & 86 & 43 & 39 \\
\hline
\end{tabular}

\section{Análise dos dados do pré e pós-teste}

Ao analisar os valores do coeficiente de variação em relação às etapas de pré e pós-teste, a dispersão em relação à média foi de $87,22 \%$ e $98,90 \%$, respectivamente. A média de participantes na fase pré-teste foi de 65 estudantes $(65,27)$ e, na fase após a palestra, 59 estudantes $(59,45)$, apresentando uma redução de aproximadamente seis estudantes $(5,82)$ por instituição de ensino.

Com relação à participação, verificou-se que, do total de discentes matriculados, a participação média dos colégios nas fases antes e depois da palestra foi de $87,14 \%$ e $77,20 \%$, respectivamente. O menor índice de participação foi de $63,89 \%$ e 54,17\%, considerando as etapas já mencionadas. Os resultados dos dados tabulados e submetidos ao teste de Wilcoxon são apresentados na Tabela 3. 
Tabela 3. Resultados do teste de Wilcoxon (p-valor) obtidos entre o pré e o pós-teste.

Table 3. Wilcoxon test results (p-value) obtained between pre and post tests.

\begin{tabular}{|c|c|c|c|c|c|c|c|c|c|c|c|}
\hline \multicolumn{5}{|c|}{ Campo } & \multicolumn{7}{|c|}{ Urbana } \\
\hline Questão & $\begin{array}{c}\text { Gonçalves } \\
\text { Jr. }\end{array}$ & $\begin{array}{c}\text { N. S. } \\
\text { Fátima }\end{array}$ & $\begin{array}{c}\text { P. } \\
\text { Baltzar }\end{array}$ & $\begin{array}{l}\text { Rio do } \\
\text { Couro }\end{array}$ & Duque & Florestal & $\begin{array}{c}\text { J. de } \\
\text { Mattos }\end{array}$ & J. XXIII & $\begin{array}{c}\text { S. } \\
\text { Vicente }\end{array}$ & Trajano & Xavier \\
\hline 1 & $0,8501^{\mathrm{ns}}$ & $0,3613^{\mathrm{ns}}$ & $0,5807^{\mathrm{ns}}$ & $1^{\mathrm{ns}}$ & $0,5716^{\mathrm{ns}}$ & $0,0917^{\mathrm{ns}}$ & $0,4098^{\mathrm{ns}}$ & $0,7865^{\mathrm{ns}}$ & $0,5839^{\mathrm{ns}}$ & $0,4098^{\mathrm{ns}}$ & $0,7525^{\mathrm{ns}}$ \\
\hline 2 & $0,8551^{\mathrm{ns}}$ & $0,1814^{\mathrm{ns}}$ & $0,5807^{\text {ns }}$ & 0,5827 ns & $0,7855^{\mathrm{ns}}$ & $0,1718^{\text {ns }}$ & $0,5896^{\mathrm{ns}}$ & $0,5807^{\text {ns }}$ & $0,8321^{\mathrm{ns}}$ & $0,4076^{\mathrm{ns}}$ & $0,6845^{\mathrm{ns}}$ \\
\hline 3 & $1^{\mathrm{ns}}$ & $0,0579^{*}$ & $0,3447^{\mathrm{ns}}$ & $0,5^{\text {ns }}$ & $0,6845^{\mathrm{ns}}$ & $0,0355^{*}$ & $0,7825^{\text {ns }}$ & $0,6788^{\mathrm{ns}}$ & $0,5248^{\mathrm{ns}}$ & $0,5807^{\mathrm{ns}}$ & $0,5271^{\mathrm{ns}}$ \\
\hline 4 & $1^{\mathrm{ns}}$ & $0,1814^{\mathrm{ns}}$ & $0^{* *}$ & $0,8539^{\mathrm{ns}}$ & $0,3447^{\mathrm{ns}}$ & $0,034^{*}$ & $0,2021^{\mathrm{ns}}$ & $0,4615^{\mathrm{ns}}$ & $0,8923^{\mathrm{ns}}$ & $0,5982^{\mathrm{ns}}$ & $0,6875^{\mathrm{ns}}$ \\
\hline 5 & $1^{\text {ns }}$ & $0,0975^{\text {ns }}$ & $0,4902^{\mathrm{ns}}$ & $0,7498^{\mathrm{ns}}$ & $1^{\mathrm{ns}}$ & $0,2918^{\mathrm{ns}}$ & $0,8923^{\text {ns }}$ & $1^{\mathrm{ns}}$ & $0,4375^{\mathrm{ns}}$ & $0,6707^{\mathrm{ns}}$ & $1^{\mathrm{ns}}$ \\
\hline 6 & $1^{\mathrm{ns}}$ & $0,0355^{*}$ & $0,5862^{\mathrm{ns}}$ & $0,8923^{\text {ns }}$ & $0,4076^{\mathrm{ns}}$ & $0,0591^{*}$ & $0,2693^{\mathrm{ns}}$ & $0,8551^{\mathrm{ns}}$ & $0,833^{\mathrm{ns}}$ & $0,7874^{\mathrm{ns}}$ & $0,2932^{\mathrm{ns}}$ \\
\hline 7 & $0,8501^{\mathrm{ns}}$ & $0,2012^{\mathrm{ns}}$ & $0,9632^{\mathrm{ns}}$ & $1^{\mathrm{ns}}$ & $0,3883^{\mathrm{ns}}$ & $0,1056^{\mathrm{ns}}$ & $0,5839^{\mathrm{ns}}$ & $0,7893^{\mathrm{ns}}$ & $0,5282^{\mathrm{ns}}$ & $0,5827^{\mathrm{ns}}$ & $0,4982^{\mathrm{ns}}$ \\
\hline 8 & $0,5^{\mathrm{ns}}$ & $0,4227^{\mathrm{ns}}$ & $0,8145^{\mathrm{ns}}$ & $0,5^{\text {ns }}$ & $0,7498^{\mathrm{ns}}$ & $0,4185^{\mathrm{ns}}$ & $0,9161^{\mathrm{ns}}$ & $1^{\text {ns }}$ & $1^{\mathrm{ns}}$ & $1^{\mathrm{ns}}$ & $0,4618^{\mathrm{ns}}$ \\
\hline 9 & $1^{\mathrm{ns}}$ & $0,1756^{\mathrm{ns}}$ & $0^{* *}$ & $0,7893^{\mathrm{ns}}$ & $1^{\mathrm{ns}}$ & $0,2228^{\mathrm{ns}}$ & $0,5839^{\mathrm{ns}}$ & $0,8551^{\mathrm{ns}}$ & $0,8551^{\mathrm{ns}}$ & $0,7127^{\mathrm{ns}}$ & $0,625^{\mathrm{ns}}$ \\
\hline 10 & $0,9997^{\mathrm{ns}}$ & $0,0541^{*}$ & $0,2373^{\text {ns }}$ & $0,0011^{* *}$ & $0,0016^{* *}$ & $0,0514^{*}$ & $0,0283^{* *}$ & $0,0114^{* *}$ & $0,0296^{* *}$ & $0,0025^{* *}$ & $0,0011^{* *}$ \\
\hline 11 & $0,5^{\mathrm{ns}}$ & $0,25^{\text {ns }}$ & $0^{* * *}$ & $1^{\mathrm{ns}}$ & $1^{\mathrm{ns}}$ & $0,25^{\mathrm{ns}}$ & $0,9132^{\mathrm{ns}}$ & $0,8145^{\text {ns }}$ & $0,75^{\mathrm{ns}}$ & $0,75^{\mathrm{ns}}$ & $1^{\mathrm{ns}}$ \\
\hline 12 & $1^{\text {ns }}$ & $0,1003^{\mathrm{ns}}$ & $0,5862^{\text {ns }}$ & $0,7835^{\text {ns }}$ & $0^{* *}$ & $0,1003^{\mathrm{ns}}$ & $0,1344^{\mathrm{ns}}$ & $0,8923^{\mathrm{ns}}$ & $0,5879^{\mathrm{ns}}$ & $0,9132^{\text {ns }}$ & $0,625^{\mathrm{ns}}$ \\
\hline Geral & $0,0086^{* *}$ & $0^{* *}$ & $0,0187^{*}$ & $0,0038^{* *}$ & $0,4025^{*}$ & $0^{* *}$ & $0,0921^{\text {ns }}$ & $0,3021^{\text {ns }}$ & $0,3614^{\mathrm{ns}}$ & $0,6292^{\mathrm{ns}}$ & $0,001^{* *}$ \\
\hline
\end{tabular}

Nota: $* *=$ altamente significativo (se p-valor for $<0,01$ ), * significativo (se p-valor for entre 0,01 e 0,05 ) e ns= não-significativo (se p-valor for $>0,05)$

Por meio da observação dos dados e análise do p-valor geral, constatou-se que 63,7\% das respostas foram significativas ou altamente significativas. Numa apreciação individual, a questão que teve maior número de respostas classificadas como significativas ou altamente significativas foi a questão 10, que se referia às espécies que compõem a Floresta Ombrófila Mista, ocorrentes em nove colégios $(81,8 \%$ das instituições de ensino avaliadas).

Pela realização do teste do qui-quadrado, obteve-se p-valor de 0,9871 , sendo a hipótese de nulidade não rejeitada. Isso indica que, estatisticamente, as frequências observadas não foram diferentes das frequências esperadas. Portanto, existe associação entre os grupos. Com relação à análise das porcentagens de respostas do questionário, as mais expressivas estão apresentadas nas Tabelas 4, 5, 6 e 7, assim como o incremento da pontuação obtida, de uma maneira geral, para todas as questões por todos os estudantes.

Tabela 4. Porcentagem das respostas mais expressivas obtidas na primeira parte do questionário.

Table 4. Percentage of the most expressive answers obtained in the first part of the questionnaire.

\begin{tabular}{ccccc}
\hline Questão & Antes & Depois & Diferença & Resposta mais expressiva \\
\hline 1 & 77 & 86,1 & 9,1 & Concordo \\
2 & 69 & 76,9 & 7,9 & Concordo \\
3 & 68,7 & 69,3 & 0,6 & Discordo \\
4 & 84,1 & 88,2 & 4,1 & Concordo \\
5 & 59 & 47,6 & $-11,4$ & Discordo \\
6 & 66,4 & 66,9 & 0,5 & Discordo \\
7 & 67,5 & 68,5 & 1 & Concordo \\
8 & 64,9 & 70,9 & 6 & Concordo \\
\hline
\end{tabular}

Tabela 5. Porcentagem das respostas mais expressivas obtidas na questão 9 do questionário.

Table 5. Percentage of the most expressive answers obtained in question 9 of the questionnaire.

\begin{tabular}{ccc|ccc}
\hline \multicolumn{2}{c|}{ Pouco conservado } & \multicolumn{3}{c}{ Conservado } \\
\hline Antes & Depois & Diferença & Antes & Depois & Diferença \\
45,5 & 46,1 & 0,6 & 46,1 & 31,1 & -15 \\
\hline
\end{tabular}

FLORESTA, Curitiba, PR, v. 48, n. 2, p. 143-152, abr/jun 2018

Iurk. M. C. et.al.

ISSN eletrônico 1982-4688

DOI: $10.5380 /$ rf.v48 i2.51179 
Tabela 6. Porcentagem das respostas obtidas na questão 10 do questionário

Table 6. Percentage of the answers obtained in question 10 of the questionnaire

\begin{tabular}{lccc}
\hline Espécie & Antes & Depois & Diferença \\
\hline Araucária & 83,2 & 91,7 & 8,5 \\
Imbuia & 46,1 & 55,5 & 9,4 \\
Cedro & 66,3 & 63,8 & $-2,5$ \\
Miguel-Pintado & 21,9 & 34,5 & 12,6 \\
Aroeira & 29,1 & 38,3 & 9,2 \\
Tarumã & 10,1 & 18,8 & 8,7 \\
Pessegueiro-Bravo & 27,4 & 32,3 & 4,9 \\
Mamica-de-porca & 18,9 & 36,2 & 17,3 \\
Bugreiro & 31,6 & 41,4 & 9,8 \\
Jerivá & 24,6 & 41,5 & 16,9 \\
Vassourão & 35,2 & 37,1 & 1,9 \\
Açoita-cavalo & 13,1 & 25,1 & 12 \\
Guabirobeira & 29,5 & 36,2 & 6,7 \\
Guamirim & 21,3 & 34,7 & 13,4 \\
Guaçatunga & 21,3 & 28,3 & 7 \\
\hline
\end{tabular}

Tabela 7. Porcentagem das respostas mais expressivas obtidas na questão 11 do questionário.

Table 7. Percentage of the most expressive answers obtained in question 11 of the questionnaire.

\begin{tabular}{ccccccccc}
\hline & Sim & \multicolumn{3}{c}{ Não } & \multicolumn{3}{c}{ Não sei } \\
\hline Antes & Depois & Diferença & Antes & Depois & Diferença & Antes & Depois & Diferença \\
45,9 & 39,4 & $-6,5$ & 42,4 & 43,2 & 0,9 & 11,8 & 17,4 & 5,6 \\
\hline
\end{tabular}

Tabela 8. Porcentagem das respostas mais expressivas obtidas na questão 12 do questionário.

Table 8. Percentage of the most expressive answers obtained in question 12 of the questionnaire.

\begin{tabular}{ccc|ccc|ccc}
\hline \multicolumn{3}{c}{ Às vezes } & \multicolumn{3}{c|}{ Não costumo frequentar esses } & \multicolumn{3}{c}{ Não sei dizer } \\
\hline Antes & Depois & Diferença & Antes & Depois & Diferença & Antes & Depois & Diferença \\
28,4 & 28,6 & 0,2 & 8,5 & 5,2 & $-3,3$ & 6,1 & 8,6 & 2,5 \\
\hline
\end{tabular}

\section{DISCUSSÃO}

A participação dos estudantes durante as duas etapas contemplou uma amostra heterogênea, devido ao número diferenciado de vagas que cada estabelecimento de ensino oferece. Verificou-se uma acentuada dispersão entre o número de estudantes presentes nos colégios participantes. Uma escola, por exemplo, contava com 12 alunos, ao passo que outra apresentava 224 estudantes colaborando com o projeto. A média de participação dos estudantes também foi bastante diversificada. Quanto a isso, vale salientar que a realização das etapas do trabalho se deu em dias diferentes e, em alguns colégios, havia um número maior de estudantes faltantes, devido ao período de intensas chuvas durante a coleta de dados.

Com relação ao total das séries analisadas, os resultados do teste de Wilcoxon indicaram que, para $63,7 \%$ das perguntas realizadas, a diferença entre o pré e o pós-teste foi altamente significativa ou significativa. Essa porcentagem invalida a hipótese nula, evidenciando a importância da palestra ministrada após o pré-teste. Além disso, pela realização do teste do qui-quadrado, a hipótese de nulidade também foi rejeitada, verificando-se diferença significativa entre o pré e o pós-teste, o que nos permitiu constatar a eficiência da palestra como ferramenta na educação ambiental mais uma vez.

A realização da palestra gerou modificações na percepção dos estudantes sobre a paisagem local, principalmente no reconhecimento das espécies que fazem parte da Floresta Ombrófila Mista. A questão que mais evidenciou a diferença entre o pré e o pós-teste foi a número 10, que avaliou a identificação de espécies comuns da Floresta Ombrófila Mista. Os únicos dois colégios que não tiveram as respostas nessa classificação estão localizados no campo, onde os estudantes possuem maior contato com remanescentes florestais e, portanto, já tinham conhecimento prévio das espécies, adquirido no cotidiano e convívio com familiares, situação inúmeras vezes relatada durantes a aplicação dos questionários.

Para a primeira questão, que se referia à temperatura do ambiente, ocorreu incremento na porcentagem das respostas. Isso pode ser observado, pois os assuntos foram trabalhados durante a palestra. Em estudo realizado em 
três comunidades de Santa Catarina, Zank et al. (2016) encontraram resultado semelhante. Foi observado que $20 \%$ dos entrevistados concordavam que a floresta colabora para que o ambiente fique mais fresco.

A terceira questão, que abordava as necessidades da comunidade e a conservação dos remanescentes florestais, apresentou decréscimo pelas respostas dos alunos, os quais acreditavam que o cuidado com a floresta não era tão importante. Podemos entender essa situação, pois foram analisadas duas situações bastante diferentes (campo e região urbana), em que as necessidades são muito distintas.

No pré-teste, o Colégio Florestal teve $4,1 \%$ dos estudantes concordando com a afirmativa de que a conservação dos remanescentes não era tão importante. Já no pós-teste, esse percentual caiu para $3,1 \%$. Um resultado totalmente inverso ocorreu no Colégio Estadual de Gonçalves Júnior, localizado no campo. No préteste, 9,5\% dos alunos concordavam com a frase, enquanto que, no pós-teste, 18,1\% concordaram com a afirmativa. Esse resultado ocorreu porque a comunidade do campo onde se localiza a escola foi colonizada por imigrantes europeus e, até os dias de hoje, a alta produção é valorizada. Nesse contexto, diante da busca pelo aumento de produção a fim de se manter inserido no mercado e de aumentar sua renda, o agricultor tem se privado de várias medidas preservativas e conservativas. As atividades não são planejadas e os impactos, provocados pela ação antrópica na maioria das vezes, são apresentados tarde em relação ao momento em que foram desenvolvidas as ações (CHAVES; FARENZENA, 2010).

$\mathrm{Na}$ questão cinco, foi perguntado sobre a possível sujeira que as árvores podem fazer. Observou-se acréscimo no número de estudantes que discordavam da afirmação. Em trabalho sobre a Avenida Cândido Abreu de Curitiba (PR), Monteiro et al. (2013) verificaram que a sujeira ocasionada pelas árvores é a principal desvantagem citada pelas pessoas. A questão seguinte (número seis), a qual dizia que os remanescentes são locais para desocupados, obteve pouco aumento na porcentagem das respostas, porém percebeu-se que ocorreu certa mudança nas respostas após a realização da palestra. Muitas vezes, regiões florestais são cenários de homicídios, frequentemente noticiados pela mídia. Segundo a Secretaria de Segurança Pública do Paraná, de 2015 para 2016 , houve um aumento de $17 \%$ nos roubos e furtos nessas regiões. Atualmente, são registrados quase mil roubos por mês na área rural do estado (SSP, 2017).

Nas questões sete e oito, alguns termos não foram muito bem compreendidos durante o pré-teste, sendo, muitas vezes, solicitada maior explicação. No entanto, no pós-teste, observou-se acréscimo na porcentagem das respostas, pois, assim como observado em outras questões, os termos foram explicados e referenciados na palestra.

Através da questão nove, percebeu-se uma compreensão do que seria um ambiente pouco conservado, pois foi observada expressiva diminuição de participantes que acreditavam que o remanescente próximo estava conservado. Segundo o Ministério do Meio Ambiente (MMA, 2017), restam menos de 3\% da área de Floresta com Araucárias quando comparada com a área original, incluindo florestas exploradas e matas em regeneração. Menos de $1 \%$ da área original guarda as características de floresta primitiva, ou seja, áreas pouco ou nunca exploradas.

Pela questão número dez, que consistia na identificação das espécies comuns da Floresta Ombrófila Mista, observou-se acréscimo na porcentagem de respostas para todas as espécies, com exceção do cedro (Cedrela fissilis Vell). No pré-teste, muitos estudantes confundiram essa espécie com o popular "cedrinho de jardim", muito comum nas residências da cidade. Depois da palestra, os alunos se mostraram surpresos ao saber que existia uma espécie nativa com esse nome.

A última questão perguntava se o estudante precisava se deslocar muito até encontrar um remanescente florestal. Esta teve um incremento de porcentagem baixo para as respostas "sim" $(0,3 \%)$, "não" $(0,3 \%)$ e "às vezes" $(0,2 \%)$, porém a resposta "não costumo frequentar esses lugares" teve um decréscimo de 3,3\%. Analisando esses dados, pode-se perceber que ocorreu uma compreensão de que o termo remanescente florestal se refere a pequenos espaços de floresta que originalmente eram áreas amplas e que foram separadas ou desligadas de uma maneira não natural, promovendo a divisão dos habitats em unidades menores e isoladas, e que possuem importância biológica e ambiental (CALEGARI et al., 2010).

Segundo Pedrini et al. (2010), a partir das percepções internalizadas em cada indivíduo, pode-se buscar a mudança de atitudes, um dos principais objetivos da educação ambiental para sociedades sustentáveis. Observa-se isso na adolescência, quando acontece uma série de modificações físicas e psicológicas importantes para o desenvolvimento do indivíduo (MOREIRA, 2011). Nesse sentido, a pessoa em desenvolvimento molda-se, muda e recria o meio no qual se encontra. De acordo com Pires e Bromberger (2007), a escola é um ambiente onde é possível e viável se realizarem ações que despertem o senso criativo, crítico e transformador de seus atores, colaborando de forma significativa para o resgate e construção da cidadania.

FLORESTA, Curitiba, PR, v. 48, n. 2, p. 143-152, abr/jun 2018

Iurk. M. C. et.al.

ISSN eletrônico 1982-4688

DOI: $10.5380 /$ rf.v48 i2.51179 


\section{CONCLUSÃO}

- A percepção ambiental é de fundamental importância, pois permite compreender o sentido da inserção do ser humano no seu ambiente. A escola deve ser o espaço educativo capaz de integrar o indivíduo ao meio ambiente por meio de ações concretas de educação ambiental.

- A palestra teve efeito positivo, promovendo modificações na percepção dos estudantes com relação à paisagem local, principalmente quanto ao reconhecimento das espécies comuns a esse ecossistema.

- A questão que avaliou a identificação de espécies comuns da Floresta Ombrófila Mista foi a que mais evidenciou a diferença entre o pré e o pós-teste. Apenas em dois colégios, localizados na área rural, as respostas não se encontraram nessa classificação, provavelmente pelo fato de os estudantes terem maior contato com remanescentes florestais.

- Para as demais questões, pode-se concluir que houve êxito na recepção de orientações sobre a importância de remanescentes florestais e de seus benefícios.

- Quanto à conservação de remanescentes, verificou-se contribuição das palestras para compreensão do que seria um ambiente pouco conservado ou conservado, pois foi observada uma expressiva diminuição dos participantes que acreditavam que o remanescente próximo ao ambiente de ensino era conservado por apenas conter um conjunto de árvores.

- Considerando a atual situação de existência da Floresta Ombrófila Mista, trabalhos de educação ambiental deverão ser cada vez mais aplicados na tentativa de mudar a visão sobre a importância das florestas para a manutenção do equilíbrio ambiental e qualidade de vida saudável.

\section{REFERÊNCIAS}

BIONDI, D.; FALKOWSKI, V. A. Avaliação de uma atividade de educação ambiental com o tema Solo. Revista Eletrônica do Mestrado em Educação Ambiental, Rio Grande, v. 22, p. 202-215, 2009.

CALEGARI, L.; MARTINS, S. V.; GLERIANI, J. M.; SILVA, E.; BUSATO, L. C. Análise da dinâmica de fragmentos florestais no município de Carandaí, MG, para fins de restauração florestal. Revista Árvore, Viçosa, v. 34, n. 5, p. 871-880, 2010. Disponível em: 〈http://www.scielo.br/pdf/rarv/v34n5/12.pdf〉. Acesso em 27/01/2017.

CARRILLO, A. C., BIONDI, D. A conservação do papagaio-da-cara-roxa (Amazona brasiliensis) no estado do Paraná - uma experiência de educação ambiental no ensino formal. Revista Árvore, Viçosa, v.31, p. 113-122, 2007.

CHAVES, M.; FARENZENA, D. Concepções de meio ambiente da população rural e suas implicações no processo de deterioração ambiental na localidade de Quilombo, Paraíso do Sul, RS. Disc. Scientia, Santa Maria, v. 11, n. 1, p. 1-16, 2010. Disponível em: <https://www.periodicos.unifra.br/index.php/disciplinarumCH/article/ viewFile/1705/1609>. Acesso em 14/01/2017.

COLLOT, M.; NEGREIROS, C. Pontos de vista sobre a percepção de paisagens. In: NEGREIROS, C.; LEMOS, M.; ALVES, I. Literatura e Paisagem em diálogo. Rio de Janeiro: Makunaima, 2012. 237 p. Disponível em: <http://s3.amazonaws.com/academia.edu.documents/32109386/literatura_epaisagem.pdf?AWSAccessKeyId=A KIAJ56TQJRTWSMTNPEA\&Expires=1484321554\&Signature=ui1EGpciqUPS3zN4Bnmn8asJHQg\%3D\&resp onsecontentdisposition=inline\%3B\%20filename\%3DLivro_Literatura_e_Paisagem_em_dialogo_h.pdf\#page=12 > Acesso em: 27/12/2016.

COSTA, R. G. S., COLESANTI, M. M. A contribuição da percepção ambiental nos estudos das áreas verdes. Raega, Curitiba, v. 22, p. 238-251, 2011.

FANDI, A. C., MELO, C. A interferência de um programa de educação ambiental no aprendizado de alunos das zonas rural e urbana. Revista educação, Santa Maria, v.26, n. 2, p. 70-80, 2001.

FIGUEIREDO-FILHO, A.; DIAS, A. N.; STEPKA, T. F.; SAWCZUK, A. R. Crescimento, mortalidade, ingresso e distribuição diamétrica em Floresta Ombrófila Mista. Floresta, Curitiba, v. 40, n. 4, p. 763-776, 2010.

Instituto Brasileiro de Geografia e Estatítica (IBGE). Cidades - o Brasil município por município. Disponível em: < http://www.cidades.ibge.gov.br/xtras/perfil.php?lang=\&codmun=411070\&search=|infogr\%E1ficos:informa\%E7\%F5es-completas $>$. Acesso em 16 set. 2016. 
MARCOMIM, F. E., SATO, M. Percepção, Paisagem e Educação Ambiental: uma investigação na região litorânea de Laguna-SC, Brasil. Educ. rev, Belo Horizonte, v. 32, n. 2, p.159-186, 2016. Disponível em: $\leq$ http://www.scielo.br/pdf/edur/v32n2/1982-6621-edur-32-02-00159.pdf>. Acesso em 17/01/2017.

MARIN, A. A. Pesquisa em educação ambiental e percepção ambiental. Pesquisa em Educação Ambiental, Curitiba, v. 3, n. 1, p. 203-222, 2008.

MINISTÉRIO DO MEIO AMBIENTE (MMA). A Floresta com Araucárias. Disponível em: <http://www.mma.gov.br/estruturas/202/_arquivos/folder_consulta02.pdf >. Acesso em 18/01/2017.

MONTEIRO, M. M. G.; TETTO, A. F.; BIONDI, D.; SILVA, R. R. S. Percepção dos usuários em relação à arborização da avenida Cândido de Abreu-Curitiba-PR. REVSBAU, Piracicaba, v. 8, n. 2, p. 20-34, 2013. Disponível em: <http://www.revsbau.esalq.usp.br/artigos_cientificos/artigo50sn-publicacao.pdf>. Acesso em: $18 / 01 / 2017$.

MOREIRA, L. M. A. Desenvolvimento e crescimento humano: da concepção à puberdade. In: Algumas abordagens da educação sexual na deficiência intelectual. 3. ed. Salvador: EDUFBA, 2011, pp. 113-123. Disponível em: < http://books.scielo.org/id/7z56d/pdf/moreira-9788523211578-11.pdf> Acesso em: 24 mai. 2017.

MUCELIN, C. A.; BELLINI, M. Lixo e impactos ambientais perceptíveis no ecossistema urbano. Sociedade \& Natureza, Uberlândia, v. 20, n.1, p. 111-124, 2008.

OLIVEIRA, J. P., ANJOS, F. A., LEITE, F. C. L. O potencial da paisagem urbana como atratividade turística: um estudo sobre a paisagem de Brasília - DF. Interações, Campo Grande, v. 9, n. 2, p. 159-169, 2008. Disponível em: <http://docplayer.com.br/829112-Josildete-pereira-de-oliveira-francisco-antonio-dos-anjos-fabiana-calcadade-lamare-leite.html> Acesso em 28/12/2016.

OLIVEIRA, T. L. F., VARGAS, I. A. Vivências integradas à natureza: Por uma Educação Ambiental que estimule os sentidos. Revista eletrônica do mestrado em Educação Ambiental. Rio Grande, v. 22, p. 309-322, 2009.

PEDRINI, A.; COSTA, E. A.; GHILARDI, N. Percepção ambiental de crianças e pré-adolescentes em vulnerabilidade social para projetos em educação ambiental. Ciência \& Educação, Bauru, v. 16, n.1, p. 163-179, 2010. Disponível em: < http://www.scielo.br/pdf/ciedu/v16n1/v16n1a10.pdf>. Acesso em: 12/01/2017.

PIRES, P. A. G.; BROMBERGER, S. M. T. A Educação Ambiental e o trabalho de cidadania com adolescentes. Ambiente \& Educação, Rio Grande, v. 12, p. 91-100, 2007. Disponível em: <file:///C:/Users/Usuario/Downloads/806-1639-1-PB\%20(1).pdf>. Acesso em 15/01/2017.

Secretaria da Segurança Pública e Administração Penitenciária do Paraná (SESP/PR). Relatório Estatístico Criminal, 2016. Disponível em: < http://www.seguranca.pr.gov.br/arquivos/File/Relatorio_Estatistico_4Trimest re_2016.pdf>. Acesso em 14/01/2017.

SIDNEY, S. Estatística não-paramétrica para as ciências do comportamento. Rio de Janeiro: Mc Graw-Hill do Brasil, 1975. 448p.

VENÂNCIO, D. L.; OLIVEIRA-FILHO, P. C.; DISPERATI, A. A. Uso do geoprocessamento em estudo ambiental na bacia hidrográfica do rio das Antas, Irati (Paraná). Ambiência, Guarapuava, v. 6, n. 1, p.135-146, 2010.

ZANK, S.; ÁVILA, J. V. C.; HANAZAKI, N. Compreendendo a relação entre saúde do ambiente e saúde humana em comunidades Quilombolas de Santa Catarina. Rev. bras. plantas med, Botucatu, v. 18, n. 1, p. 157167, 2016. Disponível em: <http://www.scielo.br/scielo.php?script=sci_arttext\&pid=S1516-

05722016000100157>. Acesso em 12/01/2017.

FLORESTA, Curitiba, PR, v. 48, n. 2, p. 143-152, abr/jun 2018

Iurk. M. C. et.al.

ISSN eletrônico 1982-4688

DOI: $10.5380 /$ rf.v48 i2.51179 
FLORESTA, Curitiba, PR, v. 48, n. 2, p 143-152, abr/jun 2018 Iurk. M. C. et.al. 